\title{
Relapsing remitting hypnic headache responsive to indomethacin in an adolescent: a case report
}

\author{
Sanjay Prakash $\cdot$ Ajay S. Dabhi
}

Received: 18 July 2008/Accepted: 11 September 2008/Published online: 30 September 2008

(C) Springer-Verlag 2008

\begin{abstract}
Hypnic headache (HH) is a rare sleep-associated primary headache disorder that usually begins after the age of 60 years. Here we report a 19-year-old male with 4year history of predominantly left sided $\mathrm{HH}$. $\mathrm{He}$ is the youngest person reported who fulfills the IHS diagnostic criteria for $\mathrm{HH}$. The patient had history of relapsingremitting course. The headache occurred every night at a constant time in each relapse. It was non-throbbing, moderate to severe, for $30 \mathrm{~min}$ to $5 \mathrm{~h}$, and usually after $3 \mathrm{~h}$ of sleep. The patient showed complete response to indomethacin $(75 \mathrm{mg}$ at bedtime). Frequent tapering of indomethacin was required to look for the remission phase.
\end{abstract}

Keywords Hypnic headache - Elderly headache · Indomethacin

\section{Introduction}

Hypnic headache $(\mathrm{HH})$ is a primary headache disorder characterized by attacks that occur only during sleep. It was first described by Raskin in 1988 [1]. Since then, about

S. Prakash

Department of Neurology, Medical College,

SSG Hospital, Baroda 390001, Gujarat, India

S. Prakash $(\square)$

O-19, Doctor's quarter, Jail road, Baroda 390001, Gujarat, India

e-mail: drprakashs@yahoo.co.in

A. S. Dabhi

Department of Medicine, Medical College, Baroda 390001,

Gujarat, India
100 similar cases have been reported in the literature. It predominantly affects elderly people [2]. However, recently two cases of probable $\mathrm{HH}$ are reported in the children less than 10 years [3, 4]. HH is possibly a chronic unremitting disorder [2]. However, few cases of episodic pattern are reported [5,6]. Lithium is the most effective drug for prophylactic treatment of $\mathrm{HH}$. Indomethacin has been suggested to be helpful in unilateral $\mathrm{HH}$ [7]. We report a case of relapsing-remitting variety of $\mathrm{HH}$ in an adolescent who showed complete response to indomethacin.

\section{Case report}

A 19-year-old male presented with a 4-year history of relapsing-remitting type of nocturnal headache, which awakened him during sleep. In each relapse, he had headache almost every night at a consistent time (about 12 a.m.), 3-4 h after he fell asleep. The periods of relapse and remission were variable, few weeks to 6 months. The remission phase was not related to any drug intake. The patient described the headache as non-throbbing and moderate to severe in the intensity. The headache was usually localized to the left frontal and temporal areas. However, it used to become bilateral in about $10 \%$ of the attacks (especially with severe attacks). He never had headache localized exclusive to the right side. The patient never felt orbital or facial pain. The usual duration of attacks was about $60 \mathrm{~min}$ (range $30 \mathrm{~min}$ to $5 \mathrm{~h}$ ). The severe and bilateral attacks used to persist for longer periods. He denied nausea, vomiting, photophobia, phonophobia, any autonomic features, and restlessness during the attacks. No relationship with dreams was noted. 
There was usually one attack per night. However, rarely, after falling back to sleep he was awakened with another similar headache, usually occurring 3-4 h after the first attack. The patient noticed that at least $3 \mathrm{~h}$ sleep was essential to get an attack. Sleep less than $3 \mathrm{~h}$ was usually not associated with headache attacks. Because of the fear of an attack, he used to wake (spontaneously or with the help of an alarm clock) within $3 \mathrm{~h}$ of the onset of sleep. He would have an attack, immediately or within an hour, if he again goes to bed in less than $60 \mathrm{~min}$ after the awakening. Waking for the 1-2 $\mathrm{h}$ was essential to avoid the headache attack in the next nocturnal nap. A nap of more than 3-4 h even during the daytime was occasionally associated with the similar type of headache.

The patient consulted in our out patient clinic in the recent relapse of the headache, that was going on for the last 2 months. He had headache almost everyday in these 2 months.

The patient was alcoholic, but did not recall any relation of alcohol intake to the onset, frequency, duration, or severity of headache. There were no precipitating or aggravating factors. There was no other significant past medical history. There was no family history of headache and history of head trauma. General and neurological examinations between two attacks and during attacks were normal. Routine hematological and biochemical screening was normal. Magnetic resonance imaging of brain and electroencephalograph revealed no abnormality. Polysomnography was not done.

He had a trial of sodium valproate $(500 \mathrm{mg}$ bid), amitryptiline $(75 \mathrm{mg}$ od), duloxetine $(60 \mathrm{mg}$ bid), naproxen (500 mg bid), ibuprofen (600 mg tds), and propranolol (60 mg bid). He could not recall any effect of these drugs in the frequency or severity of headache. Treatment with oral sumatriptan $(100 \mathrm{mg})$, oral rizatriptan $(5 \mathrm{mg})$, and oxygen inhalation during an attack provided no relief.

The patient was treated with indomethacin. It was ineffective with $25 \mathrm{mg}$ dose (bedtime). Gradually increasing the dose to $75 \mathrm{mg}$ at the bedtime (over 4 days) produced complete relief. He had no attack of any headache for next 3 weeks. He left the drug suspecting this improvement as natural remission. However, headache recurred on the second day. Drug was restarted with the same dose and response was noted on the same day. As patient had relapsing-remitting course in the past, slow tapering (over 7 days) was tried on two occasions in the next 2 months. First trial was unsuccessful. The second trial was successful and patient did not have any type of headache in the next 3 months. However, his symptoms recurred after 3 months. This relapse responded immediately with $75 \mathrm{mg}$ indomethacin at bedtime. Indomethacin was again successfully tapered after 6 weeks. There was no relapse in the next 3 months follow up.

\section{Discussion}

This patient presented with a type of headache fulfilling the International Headache Society (IHS) criteria of HH. HH is incorporated into group 4 of the IHS classification in the subheading of "other primary headaches" [8]. The differential diagnosis of headache with an exclusive onset during sleep includes secondary headache and primary headaches such as migraine, trigeminal autonomic cephalalgias and HH. Exclusion of intracranial disorders and differentiation from one of the trigeminal autonomic cephalalgias is recommended in the patient of $\mathrm{HH}$ in the IHS diagnostic criteria [8]. The features against the diagnosis of cluster headache $(\mathrm{CH})$ were the absence of autonomic features and restlessness, no response to triptans and oxygen inhalation during the attacks, and response to indomethacin as a preventive therapy. The absence of autonomic features, duration up to $5 \mathrm{~h}$, only one attack per day, and bilateral involvement in few attacks were against the diagnosis of paroxysmal hemicrania. However, $10 \%$ patients of $\mathrm{HH}$ may have mild autonomic features [2].

$\mathrm{HH}$ is considered as a disease of elderly. The mean age at onset of headache is 63 years[2].The onset after the age of 50 years is one of the features in the IHS diagnostic criteria of HH (although not essential) [8]. The age of onset in our patient was 15 years. To the best of our knowledge, he is the youngest person reported who fulfills the diagnostic criteria for HH. There are two case reports of probable $\mathrm{HH}$ in the literature younger than 15 years $[3,4]$. Besides the age, these two patients did not fulfill the criteria regarding the frequency of attacks per month. The frequency of more than 15 attacks per month is essential in a person less than 50 years of age [7]. Grosberg et al. [3] reported a 9-year-old girl with hypnic-like headache with frequency of 2-3 attacks per week. Recently, Scagni et al. [4] described an 8-year-old girl with a 5-year history of hypnic-like headache with frequency of one attack per month, and suggested that lower frequency might be observed in children with HH. These two cases and our observation suggest that the age range at onset may be broader than initially claimed.

The ratio of bilateral to unilateral is 3:2. Most of the attacks in our patient were localized to the left side. The intensity of pain is moderate to severe in more than $95 \%$ patients in the literature [2]. The few severe attacks of our patients used to become bilateral. This observation is not reported in the literature.

The usual time of onset of the headache attacks in the course of sleep is $2-4 \mathrm{~h}$ after falling asleep. Only $4 \%$ of patients had attacks within $1 \mathrm{~h}$ after falling asleep [2]. Three hours sleep was usually required to get an attack of headache in our patient. Patient had developed unique way to avoid an attack. He started to take frequent break in his 
nocturnal sleep. The average duration of attacks is about $1 \mathrm{~h}$. However, the range may be 15-360 min. The maximum duration of an attack in our patient was about $5 \mathrm{~h}$. The average frequency of headaches is about 1.2. However, the patients may have six attacks per night to one in a week [2].

Little is known about the natural history of HH. Few authors have classified HH into two different forms, chronic and episodic form. The episodic form is further subdivided into two types, episodic with no recurrence, and relapsing and remitting variety (and relapse is not because of withdrawal of the effective drug). Episodic form without recurrence may show spontaneous resolution or sustained remission even after withdrawal of the effective drug [5, 6].Our case was relapsing-remitting type. This is the least reported type of $\mathrm{HH}$. There are only six cases of relapsingremitting type in the literature (and 5 of them were reported recently) $[5,9]$.

Lithium (300-600 $\mathrm{mg}$ at the bedtime) is the most effective drug for the patients with HH [5]. The efficacy similar to lithium could be obtained with caffeine, flunarizine, and indomethacin [2]. Indomethacin is supposed to be helpful in $\mathrm{HH}$ only if the attacks are unilateral [7]. The response to indomethacin in our patient confirms this notion (as our patient had predominantly unilateral headache). However, recently Buzzi et al. [10] and Peters et al. [11] reported indomethacin responsive $\mathrm{HH}$ in patients with bilateral and holocephalic pain. The effective dose of indomethacin for the patients of $\mathrm{HH}$ is $25-150 \mathrm{mg}$ at bedtime (mean $75 \mathrm{mg}$ ). The response to indomethacin is usually immediate. There was temporal relation in the disappearance of headache and the administration of indomethacin on four occasions in the patient. Immediate reappearance of the headache after withdrawal of indomethacin was noted on two occasions. These observations indicate that indomethacin was pivotal for remission phase of HH. However, we cannot rule out the possibility of coincidence (disappearance of headache and the administration of indomethacin) in our patient, as he had many episodes of spontaneous relapse and remission in the past.

The relative rarity of $\mathrm{HH}$ has made it difficult to study its pathophysiology. The reason as to why few primary headache (including $\mathrm{HH}$ ) disorders are indomethacin sensitive is unknown. The effects of many other drugs (such as lithium, melatonin, caffeine, flunarizine, etc.) in the patients of $\mathrm{HH}$ suggest that pathophysiology may be heterogeneous [2].

The adverse effects of indomethacin in the patients of $\mathrm{HH}$ are largely unknown as long-term follow up is lacking in the literature. However, it is $10-30 \%$ in the various indomethacin responsive headaches [12]. Although indomethacin is used as a single dose (bedtime) in HH (bid or tds in other headache disorders), it is difficult to predict the incidence of side effects as most of the patients are elderly. Daytime headaches were one of the unique side effects of indomethacin in the patients of $\mathrm{HH}$ (not reported with other types of headache) [7].

In conclusion, our case broadens the range of onset of $\mathrm{HH}$. Moreover, this case suggests that frequent tapering of the effective drug should be done to look for the spontaneous resolution or relapsing-remitting variety of $\mathrm{HH}$.

Acknowledgments No grant or support was received. Written informed consent was taken from the patient to publish the report.

Conflict of interest None.

\section{References}

1. Raskin NH (1988) The hypnic headache syndrome. Headache 28:534-536

2. Evers S, Goadsby PJ (2003) Hypnic headache: clinical features, pathophysiology and treatment. Neurology 60:905-909

3. Grosberg BM, Lipton RB, Solomon S, Ballaban-Gil K (2004) Hypnic headache in childhood? A case report. Cephalalgia 25:60-70

4. Scagni P, Pagliero R (2008) Hypnic headache in childhood: a new case report. J Paediatr Child Health 44(1-2):83-84

5. Liang J-F, Fuh J-L, Yu H-Y, Hsu C-Y, Wang S-J (2008) Clinical features, polysomnography and outcome in patients with hypnic headache. Cephalalgia 28:209-215

6. Lisotto C, Mainardi F, Maggioni F, Zanchin G (2004) Episodic hypnic headache? Cephalalgia 24:681-685

7. Dodick DW, Jones JM, Capobianco DJ (2000) Hypnic headache: another indomethacin-responsive headache syndrome? Headache 40:830-835

8. Headache Classification Subcommittee of the International Headache Society (2004) The International Classification of Headache Disorders, 2nd edn. Cephalalgia 24(Suppl 1):1-160

9. Martins IP, Gouveia RG (2001) Hypnic headache and travel across time zones: a case report. Cephalalgia 21:928-931

10. Buzzi MG, Cologno D, Formisano R, Caltagirone C (2005) Hypnic headache responsive to indomethacin: second Italian case. Funct Neurol 20(2):85-87

11. Peters N, Lorenzl S, Fischereder J, Bötzel K, Straube A (2006) Hypnic headache: a case presentation including polysomnography. Cephalalgia 26:84-86

12. Pareja JA, Caminero AB, Franco E et al (2001) Dose, efficacy and tolerability of long-term indomethacin treatment of chronic paroxysmal hemicrania and hemicrania continua. Cephalalgia 21:906-910 